Proceedings

\title{
CultUnity3D: A Virtual Spatial Ecosystem for Digital Engagement with Cultural Heritage Sites ${ }^{\dagger}$
}

\author{
Estefanía López Salas 1,*, Adrián Xuíz García ${ }^{2}$, Ángel Gómez ${ }^{3}$ and Carlos Dafonte ${ }^{3}$ \\ 1 School of Architecture, Department of Project Design, Urbanism and Composition, Universidade da \\ Coruña, Campus de A Zapateira s/n, 15071 A Coruña, Spain \\ 2 CITIC, Universidade da Coruña, Campus de Elviña s/n, 15071 A Coruña, Spain; adrian.xuizg@udc.es \\ 3 CITIC-Department of Computer Science and IT, Universidade da Coruña, Campus de Elviña s/n, \\ 15071 A Coruña, Spain; angel.gomez@udc.es (Á.G.); carlos.dafonte@udc.es (C.D.) \\ * Correspondence: estefania.lsalas@udc.es \\ + Presented at the 3rd XoveTIC Conference, A Coruña, Spain, 8-9 October 2020.
}

Published: 20 August 2020

\begin{abstract}
In order to help enhance public outreach and understanding of historical sites, we developed a virtual spatial ecosystem called CultUnity3D. It consists of a set of components specifically implemented within the Unity engine that enable the user to virtually explore spatial changes over time in two different modes, and to learn about the past of a built environment through the integration of and interaction with research sources and narrative. Although we built CultUnity3D for a particular case study, which is the monastic site of San Julián de Samos (Spain), this in-progress virtual ecosystem has been thought out and designed for continued and reusable development.
\end{abstract}

Keywords: virtual reality; 3D modeling; Unity; spatiotemporal simulation; digital art and architectural history

\section{Introduction}

Digital representations have become essential tools to increase public awareness and enhance understanding of cultural heritage sites. The ICOMOS charter (2008) highlights the importance of an effective interpretation and presentation of places of historical and cultural significance as a way to communicate their values, to ensure their conservation, and to promote further "interest, learning, experience, and exploration" by the public at large ([1], p. 4).

However, to digitally represent and effectively communicate the research about historical built environments is a challenge. New complexities arise when we aim to create a virtual product to disseminate knowledge about historical sites that is not only simple and attractive to engage broader audiences, but it is also as intellectually and technically rigorous as other longer established methods of dissemination. For this purpose, the London Chapter for the Computer-Based Visualization of Cultural Heritage (2009) expresses both the need to clearly document the data sources (physical remains, archival documents, photographs, etc.) on which the digital re-constructions are based and the status of the knowledge that they represent (evidence vs. hypothesis) within an integral final output [2] (pp. 2, 7-8). In this paper, we report our in-process work to create CultUnity3D, which is the first release of a virtual ecosystem that aims to make the spatial transformations of the monastic site of San Julián de Samos over time more accessible, meaningful and experiential to all-aged audiences. 


\section{Project Background}

San Julián de Samos is the most important Benedictine monastery in the French Way to Santiago de Compostela in Galicia. It has been listed as a historical monument since 1944 as it presents significant values from the past. Founded around the mid-sixth century, this building and its context evolved for centuries through successive constructions, re-constructions and demolitions that created, changed, or caused the loss of the monastic site at Samos.

Based on previous studies, archival documentation, and on-site investigation, we generated a series of phased 2D maps and 3D models that address and visualize questions of change over time [3]. As researchers, these computer-aided design (CAD) outputs help us to gain knowledge about the site, but the following questions remain: How can we communicate this outside academia and, by doing so, promote learning about cultural heritage? In which way could we represent the makings and shaping of a historical site as an ongoing process where both space and time are involved? Is it possible to create a digital ecosystem where multiple architectural models are visualized together with disparate historical datasets opened to scientific assessment and public engagement in an accessible and interactive way? To give a proper answer to the previous questions, we developed CultUnity3D.

\section{Functionalities and Components}

For the development of this virtual ecosystem, the designs in CAD format of the real environment to be modeled have been used as a base, converting and adjusting them to a $\mathrm{D}$ format for subsequent import into the Unity engine. The creation of the customizable functionalities and components (controllers, buttons, effects, etc.) have been implemented using C\# scripts integrated inside Unity [4]. The functionalities and components of CultUnity3D are as follows.

\subsection{Space and Time Interaction}

The movement of the user through the virtual model utilizes existing Unity navigation tools. In this way, it is able to experience movement in and around the building (spatial interaction). However, to discover how the monastic site was transformed at distinct time periods (time interaction), we implement a specific component: AgeController.

\subsection{Mode Controller: First Person Control and Guided Time Travel}

Two types of Virtual Reality exploration are available through the ModeController script: First Person Control, which enables the user to choose the view and path to be explored at will ([5], pp. 147-148), and Guided Time Travel, which turns the user into a passive observer to watch a predefined tour set.

\subsection{Integration of Research Sources and Narrative}

The virtual reconstruction of the historical site in CultUnity3D aims to be a self-explanatory product where we integrate the architectural models and plans, the research sources and a brief narrative of the site's biography [6], pp. 488-490. To allow users access to data connected to what they are exploring in the scene, thus far, we have defined the components AnimationButton, FocusButton, ImageAndAudioButton and SwitchButton (see Figure 1). 


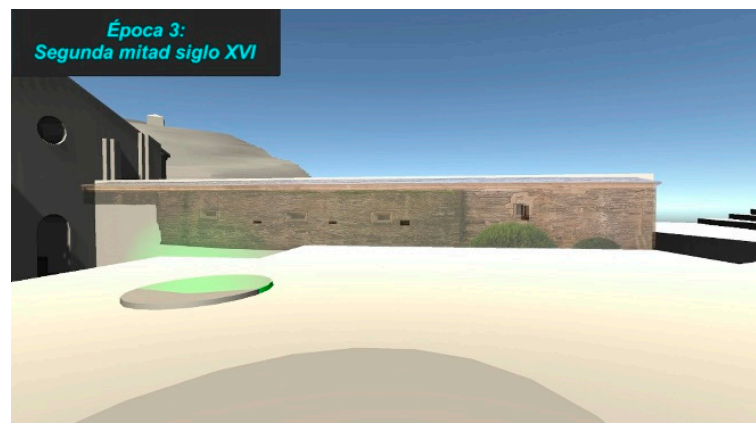

(a)

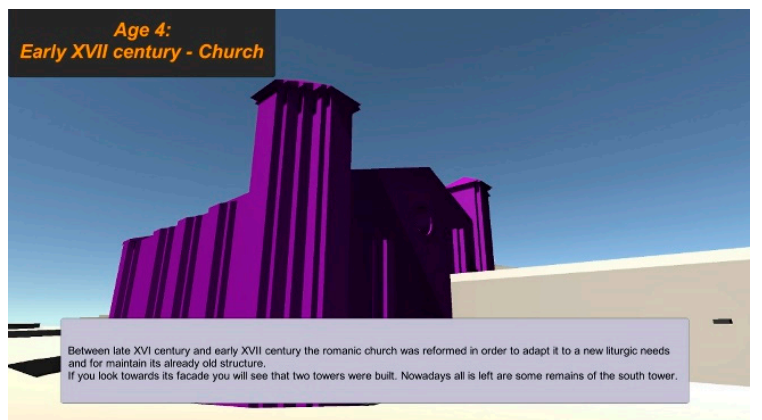

(b)

Figure 1. Screenshots of two interactive buttons designed: (a) to display graphic research sources, and (b) to give access to a brief textual and audio narrative.

\subsection{Reusable and User-friendly Infrastructure}

Instead of building a project-specific solution, CultUnity3D aims to provide a tool set of reusable features for future case studies, where the visualization of spatial change over time is the main art historical question to tackle and communicate. Moreover, our in-progress ecosystem is conceived to enable a user-friendly future development and customization run not only by experts in programming, but also scholars in art, architectural and urban history. CultUnity3D can also be easily adapted to different display devices, including touch screens or 3D glasses for virtual reality environments.

\section{Conclusions}

Through CultUnity3D, we create a virtual ecosystem where the understanding of a cultural heritage site with a complex long life is possible. This is not a completed project, but a first step with open opportunities, and also new challenges to face in future developments. For instance, we must work on the usability of the navigation controls and the user interface (menu, instructions, graphical UI elements, etc.). We also need to implement new components to increase the interaction between the user and the model in different devices. The spatiotemporal functionality needs to be improved (time slider, multi-mode viewer, ...) to provide a different understanding than is possible with static images. We need to work on the Guided Time Travel to offer the user thoughtful, predefined tours within a virtual historical site. In this sense, we also consider it important to continue working on the integration of historical data and its display in the user interface. The visualization of spatial changes over time with disparate research sources and physical evidence for public dissemination demands new answers, but it also opens up new ways to think about and produce knowledge.

Author Contributions: All authors have equally contributed to this paper. All authors have read and agreed to the published version of the manuscript.

Funding: This research received no external funding.

Conflicts of Interest: The authors declare no conflict of interest.

\section{References}

1. The ICOMOS Charter for the Interpretation and Presentation of Cultural Heritage Sites; ICOMOS: Paris, France, 2008. Available online: https://www.icomos.org/en/resources/charters-and-texts (accessed on 13 June 2020).

2. The London Chapter for the Computer-Based Visualization of Cultural Heritage; London, UK, 2009. Available online: http://www.londoncharter.org/downloads.html (accessed on 13 June 2020).

3. López Salas, E. San Julián de Samos-Lugo, Estudio e Interpretación del Diseño Monástico y su Evolución. Ph.D. Thesis, Universidade da Coruña, A Coruña, Spain, 2015.

4. Xuíz García, A. Sistema de Representación Virtual Interactiva do Modelo Dunha Estrutura Arquitectónica de alto valor Cultural. Ph.D. Thesis, Universidade da Coruña, A Coruña, Spain, 2020.

5. Tan, B.K; Hafizur, R. Virtual Heritage: Reality and Criticism. In Joining Languages, Cultures and Visions: CAADFutures 2009; Tidalfi, T., Dorta, T., Eds.; Presses de l'Université de Montréal: Montréal, QC, Canada, 2009, pp. 143-156. 
6. Wendell, A.; Ozludil Altin, B.; Thompson, U. Prototyping a Temporospatial Simulation Framework: Case of an Ottoman Insane Asylum. In Complexity \& Simplicity-Proceedings of the 34th International Conference on Education and Research in Computer Aided Architectural Design in Europe; Herneoja, A., Österlund, T., Markkanen, P., Eds.; eCAADe and Oulu School of Architecture: Brussels, Belgium, 2016; Volume 2, pp. 485-491.

(C) 2020 by the authors. Licensee MDPI, Basel, Switzerland. This article is an open access article distributed under the terms and conditions of the Creative Commons Attribution (CC BY) license (http://creativecommons.org/licenses/by/4.0/). 